\title{
Chapter 3 \\ Economic Impact Assessment of Entrepreneurship Policies with the GMR-Europe Model
}

\author{
Attila Varga, László Szerb, Tamás Sebestyén and Norbert Szabó
}

\begin{abstract}
This chapter introduces the most recent version of the geographic macro and regional (GMR) Europe model. The model estimates the economic impacts of policies that aim at improving the quality of entrepreneurship ecosystems. As such, GMR-Europe is the first available economic impact assessment model that estimates the effects of entrepreneurship policies on several economic variables like productivity, GDP, employment, and wages. To measure the quality of regional entrepreneurial ecosystems, GMR-Europe integrates the Regional Entrepreneurship and Development Index (REDI) into its structure. In addition to introducing the GMR-Europe
\end{abstract}

This study was financed by the Financial and Institutional Reforms for an Entrepreneurial Society (FIRES) that has received funding from the EU's Horizon 2020 research and innovation program under grant agreement No. 649378 and by the European Union and Hungary co-financed by the European Social Fund through the project EFOP-3.6.2-16-2017-00017, titled "Sustainable, intelligent and inclusive regional and city models". The research has been conducted as part of the National Excellence in Higher Education Program in Hungary (reference number of the contract: 207653/2018/FEKUTSTRAT). The authors of this chapter are indebted to the following colleagues for their invaluable assistance: Gallusz Abaligeti and Dániel Kehl, for their contribution to the empirical calibration of the TFP model equations, Anna Csajkás and Richárd Farkas for their assistance in data collection, data preparation and contribution to estimations and Péter Járosi, whose previous engagement in model development and continuous assistance through this work is an inevitable part of the present model setup. Laszlo Szerb and Attila Varga also gratefully acknowledge support from the National Scientific Research Fund of Hungary (OTKA/NKFI grant no. 120289 titled Entrepreneurship and Competitiveness investigations in Hungary based on the Global Entrepreneurship Monitor surveys 2017-2019). Thanks to Andrea Herrmann for comments on earlier drafts of this chapter.

A. Varga $(\bowtie) \cdot$ L. Szerb · T. Sebestyén · N. Szabó

Regional Innovation and Entrepreneurship Research Center, MTA-PTE Innovation and Economic Growth Research Group, University of Pécs, Pécs, Hungary

e-mail: vargaa@ktk.pte.hu

L. Szerb

e-mail: szerb.laszlo@ktk.pte.hu

T. Sebestyén

e-mail: sebestyent@ktk.pte.hu

N. Szabó

e-mail: szabon@ktk.pte.hu

(C) The Author(s) 2020

M. Sanders et al. (eds.), The Entrepreneurial Society, International Studies

in Entrepreneurship 44, https://doi.org/10.1007/978-3-662-61007-7_3 
model, we provide simulations illustrating the capabilities of the model by providing estimates of the economic impacts of policies designed to improve the quality of entrepreneurial ecosystems. The analysis communicates an important message for policymakers demonstrating that the impacts of entrepreneurship policies vary across regions and countries in Europe depending on several territorial features.

Keywords Entrepreneurship policy $\cdot$ Entrepreneurial ecosystems $\cdot$ Economic growth $\cdot$ GMR models $\cdot$ REDI $\cdot$ Regional development

\subsection{Introduction}

Recently published papers report a positive influence of entrepreneurship on economic growth. Lafuente et al. (2016) emphasize that efficiency at the national level is largely supported by a healthy system of entrepreneurship. This finding gets additional support in a cross-country study of Acs et al. (2017), which concludes that entrepreneurship triggers productivity. Prieger et al. (2016) and Lafuente et al. (2019) test the entrepreneurship-growth nexus and find that national entrepreneurial ecosystems positively and significantly influence economic growth in developing countries. In Szerb et al. (2018), the entrepreneurship ecosystem influences gross value added and employment growth positively in 125 European Union regions.

Despite the fact that evidence on a positive nexus between entrepreneurship and growth is increasing, the extent to which given policy interventions (e.g., the support of entrepreneurial culture or increased financial support to entrepreneurs) affect economic growth is still not known. Furthermore, it is still not clear to what extent entrepreneurship policy is comparable with traditionally applied instruments like R\&D or human capital promotion. How would a policy combining entrepreneurship promotion and those traditional instruments affect economic growth? The relevant answers to these queries can only be found by applying specifically constructed economic impact models.

Economic impact estimation provides important information about the likely effects of policy interventions on national or regional economic performance. Policy impacts may be calculated ex-ante (in the design phase) and ex-post (after interventions have been implemented). Economic models are commonly used instruments of impact evaluation. The QUEST (Ratto et al. 2009) and the HERMIN (Bradley 2006) models have been the most frequently used tools of European Cohesion Policy impact assessment, whereas the REMI model (Treyz et al. 1992) is a widely applied instrument of regional policy evaluation in the USA.

However, the economic impact models mentioned above estimate policy impacts either at the macroeconomic (national) or at the regional (sub-national) levels. It is argued that in order to appropriately account for policy effects, economic impact models should represent both (i.e., the regional and the national) dimensions (Varga 2017a). As many development policy interventions are regionally targeted, a suitable economic impact model to estimate their effects should incorporate the regional 
dimension. Interregional interactions (trade, migration, technology spillovers) are also necessarily involved, as they tend to significantly affect the target region as well as other territories connected to it. Understanding the extent to which some relevant supra-regional units (i.e., the country or the European Union) are affected by regional level interventions may become very relevant in policy design and ex-post policy evaluations. This supports the involvement of the macroeconomic dimension in the model framework. Moreover, interventions at the national and supra-national levels (e.g., monetary or fiscal policies) significantly influence the environment within which regions develop, providing a further argument for the integration of macroeconomic and regional dimensions in development policy impact evaluation models.

With combined multi-regional/macro models, the economic impacts of different development scenarios become comparable at regional and supra-regional levels. Geographic, macro and regional (GMR) models integrate such geographic dimensions. Therefore, in this chapter, we apply the recently extended GMR-Europe model (Varga et al. 2018) in entrepreneurship policy impact estimations.

Nevertheless, at least two major challenges have to be solved in order to successfully estimate the growth effects of entrepreneurship policy with an economic impact model. The first is measuring the changes in the entrepreneurial ecosystem in relation to different interventions that aim to promote it. To date, there exists only one measure of this kind, the recently developed Regional Entrepreneurship and Development Index (REDI) (Szerb et al. 2017). The other challenge is integrating entrepreneurship into an economic impact model to estimate the economic effects of entrepreneurship policy at the relevant spatial scales. To respond to this second challenge, we integrated REDI into the framework of the GMR-Europe policy impact model (Varga et al. 2019). As a result, the most recent version of GMR models became the first available tool to estimate the economic impacts of entrepreneurship policies.

This chapter introduces the REDI in Section Two and the GMR-Europe model in Section Three. For readers who are interested in the technical details of the model, Varga et al. (2018) provide more information. To illustrate the capabilities of the GMR-Europe model in the impact estimations of entrepreneurship policies, we present a counterfactual analysis in the fourth section of this chapter. In these simulations, we assume that the quality of the entrepreneurial ecosystem gets the same relative increase in every NUTS2 region of Europe. The analysis communicates an important message for policymakers demonstrating that the economic impacts of entrepreneurship policies (measured by the change in GDP) vary across regions and countries in Europe depending on several territorial features. The chapter concludes with a summary section. 


\subsection{Measuring Regional Entrepreneurship Ecosystems: The REDI Model}

In order to examine the effect of entrepreneurship on any performance indicators like productivity, economic growth, or development, one needs clear definitions, proper measurement units, and a suitable model which supports the analysis. Currently, there is no agreement among entrepreneurship scholars on any of these preconditions (Landström and Harirchi 2018).

According to Wennekers and Thurik (1999), entrepreneurship is an ill-defined concept, while others view it as eclectic (Audretsch et al. 2015); it is difficult to find even a minimum agreement on how to frame the phenomenon (Shane and Ventakaraman 2000). Yet, a distinctive feature of entrepreneurship is its focus on the individual as opposed to firms or markets. Some identify entrepreneurs based on specific psychological traits (Baum et al. 2014), others associate it with new venture creation (Gartner 1985), and some with its economic and societal effects (Baumol 1996).

Entrepreneurship is used by many different disciplines (Low and MacMillan 1988; Parker 2018). Here, we follow mainly the approach of economics by examining how entrepreneurship affects the economic output from the measurement perspective (Acs et al. 2014). Some believe that entrepreneurial attitudes such as preferences for selfemployment, assertiveness toward entrepreneurs and entrepreneurial careers, and perceptions of entrepreneurial skills play an important role in the startup process and, ultimately, in economic growth. However, attitudes are not actions, and the exploration of the mechanism that leads attitudes into action and economic growth has not been unveiled and understood (Autio et al. 2013).

A popular approach is to identify entrepreneurship with some output measures like the startup rate or the Global Entrepreneurship Monitor (GEM) total-earlystage entrepreneurial activity ratio. The drawback of the output view is that it mixes very different measures where all can have varying effects on economic outcomes (Nightingale and Coad 2014; Vivarelli 2013). Moreover, entrepreneurial outputs and their composition vary over development (Naudé 2010; Liñán and Fernandez-Serrano 2014).

Since the seminal work of Baumol (1996), we know that the effect of entrepreneurship is regulated by its context. Framework measures like the World Bank Doing Business or the Index of Economic Freedom aim to quantify the effect of the widely interpreted institutions ${ }^{1}$ on entrepreneurship outputs, albeit better institutions are not directly linked to some entrepreneurial actions. While the maturity of the institutions is closely correlated with long-term economic development, their predictive power on growth or productivity is only partially understood (Acs et al. 2014). Besides, institutions are geographically bounded and place-based; many of them are effective and worth measuring in a smaller territorial unit than a country (Qian et al. 2013).

\footnotetext{
${ }^{1}$ We interpret institutions as formal and informal institutions that shape entrepreneurial attitudes of the population, the abilities of the entrepreneurs, and aspirations of startups.
} 
In the 2010s, a new research direction, the entrepreneurship ecosystem (EE) approach emerged focusing on the systemic (framework) conditions that lead to the occurrence of potentially high impact entrepreneurial output-so-called fast-growing gazelles (Malecki 2018; Stam 2015). While EE is still in a very early stage of development as a scientific concept, its approach is useful for examining the economic effect of entrepreneurship (Alvedalemn and Boschma 2017). Szerb et al. (2018) characterize the basic features of $\mathrm{EE}$ as (1) the clear distinction of entrepreneurial environment and entrepreneurial outputs, whereby (2) the performance of the EE depends on the systemic interaction between institutions and various players, (3) agglomeration economies, networking, and spillover effects are the basic features and mechanisms of the ecosystems, and (4) ecosystems are very different resulting from a path-dependent development process with forward and backward linkages.

There is an agreement among advocates of EE that each entrepreneurial ecosystem is unique, and the replication of successful examples is not possible. Some even believe that EEs are so unique that it is impossible to measure them. Consequently, EEs should be examined by individual case studies and their development strategy should be unique, place-, and case-based (Spigel 2017). Partially contradicting to this approach, we believe that there are some common elements of EEs and that a common measurement can be a useful tool for tailor-made policy recommendations. At present, there exists only one tool, the Regional Entrepreneurship and Development Index (REDI), which provides a measure of EE for a mix of 125 NUTS1 and NUTS2 European Union regions (Szerb et al. 2017). REDI is a regional version of the well-known Global Entrepreneurship Index (GEI) defining the system of entrepreneurship (SE) as “... the dynamic, institutionally embedded interaction between entrepreneurial attitudes, ability, and aspirations, by individuals, which drives the allocation of resources through the creation and operation of new ventures" (Acs et al. 2014, p. 119). REDI is a measure of a very complex and multidimensional quality of the entrepreneurship ecosystem. As compared to GEI, REDI is not simply a more precise, but also a more appropriate measure of EE because it incorporates a different set of institutional variables reflecting the regional forces of agglomeration, connectivity, and clustering that interact with individual entrepreneurial features.

In what follows, we provide an outline of the REDI index. For more details on the technical aspects of REDI construction, we refer to a detailed technical report (Szerb et al. 2017). The composition of REDI follows the common composite indicator building methodology with three exceptions (Joint Research Centre of the European Commission 2008). First, the construction of some variables includes some agglomeration effects. Second, we use the equalization of the averages methodology to equalize the marginal effects of the potential policy steps. Third, we use the penalty for bottleneck method to identify the optimal combination of the fourteen pillars. We follow a six-level index-building methodology starting from (1) 60 sub-indicators, then (2) creating 44 indicators, followed by (3) calculating 28 variables, (4) 14 pillars, (5) three sub-indices, and finally (6) the single REDI super-index (for details see Szerb et al. 2017). 
The three sub-indices of attitudes (ATT), abilities (ABT), and aspiration (ASP) constitute the entrepreneurship super-index, which is called REDI. All three subindices contain four or five pillars, which can be interpreted as quasi-independent building blocks of this entrepreneurship index. Each of the 14 pillars is the result of the multiplication of an individual variable and an associated institutional variable. In this case, institutional variables can be viewed as particular (region level) weights of the individual variables. Table 3.1 provides a detailed picture of the sub-indices.

Unlike other EE approaches, REDI clearly defines how the different elements are interrelated. REDI elements can have an additive (indicator level) or a multiplicative (variable level) influence on the system performance. The novelty of this method is that it portrays the entrepreneurial disparities among EU regions and provides country and regional level, tailor-made public policy suggestions to improve the level of entrepreneurship and optimize resource allocation over the different pillars of entrepreneurship.

Entrepreneurship is defined as the interaction of entrepreneurial attitudes, abilities, and aspirations. The penalty for bottleneck (PFB) methodology is developed for measuring and quantifying these interactions (Rappai and Szerb 2011). A bottleneck is defined as the worst performing element, the weakest link, or binding constraint in the system. With respect to entrepreneurship, we define a bottleneck as a shortage, or the lowest level of a particular entrepreneurial pillar as compared to other pillars. The sub-indices are composed of four or five components, defined as pillars that should be adjusted in a way that takes this notion of balance into account. After normalizing the scores of all the pillars, the value of each pillar in a region is penalized by linking it to the score of the pillar with the weakest performance in that region. This simulates the notion of a bottleneck, and if the weakest pillar were improved, the particular sub-index and ultimately the whole REDI would likewise show a material improvement. On the contrary, improving a relatively high pillar value will presumably enhance only the value of the pillar itself and cause a much smaller increase of the whole REDI. Summarizing the REDI technique intuitively, it is an index that combines information from many variables at the individual and regional level, assumes that institutions complement individual action (multiplicative), while for the total score the least performing elements weight more than the best ones, and finally a well-balanced ecosystem without bottlenecks scores higher.

This notion of bottlenecks is important for policy purposes. Our model suggests that attitudes, ability, and aspiration interact, and if they are out of balance, productive entrepreneurship is inhibited. REDI has the capacity to demonstrate how resource allocation can be optimized along the 14 pillars to improve the REDI score and, ultimately, the regional entrepreneurship system performance. Moreover, the systemic combination of the pillars influences the effectiveness of the ecosystem. An improvement in the weakest pillar would produce an increase in the overall REDI score. An EE with a homogeneous pillar configuration is viewed to be optimal (Szerb et al. 2017). The Appendix provides a concise description of the REDI methodology. Tables 3.2 and 3.3 below provide regional REDI values and country REDI scores based on population-weighted average REDI scores. 
Table 3.1 Structure of the Regional Entrepreneurship and Development Index

\begin{tabular}{|c|c|c|c|}
\hline & Sub-indices & Pillars & $\begin{array}{l}\text { Variables } \\
\text { (individual/institutional) }\end{array}$ \\
\hline \multirow{27}{*}{$\begin{array}{l}\text { Regional } \\
\text { Entrepreneurship } \\
\text { and Development } \\
\text { Index }\end{array}$} & \multirow{10}{*}{$\begin{array}{l}\text { Entrepreneurial } \\
\text { Attitudes } \\
\text { Sub-index }\end{array}$} & \multirow{2}{*}{$\begin{array}{l}\text { Opportunity } \\
\text { perception }\end{array}$} & Opportunity recognition \\
\hline & & & Market agglomeration \\
\hline & & \multirow[t]{2}{*}{ Startup skills } & Skill perception \\
\hline & & & Quality of education \\
\hline & & \multirow[t]{2}{*}{ Risk acceptance } & Risk perception \\
\hline & & & Business risk \\
\hline & & \multirow[t]{2}{*}{ Networking } & Know entrepreneurs \\
\hline & & & Social capital \\
\hline & & \multirow[t]{2}{*}{ Cultural support } & Carrier status \\
\hline & & & Open society \\
\hline & \multirow{7}{*}{$\begin{array}{l}\text { Entrepreneurial } \\
\text { Abilities } \\
\text { Sub-index }\end{array}$} & \multirow[t]{2}{*}{ Opportunity startup } & Opportunity motivation \\
\hline & & & Business environment \\
\hline & & Technology Adoption & Technology level \\
\hline & & \multirow[t]{2}{*}{ Human capital } & Educational level \\
\hline & & & Education and training \\
\hline & & \multirow[t]{2}{*}{ Competition } & Competitors \\
\hline & & & Business strategy \\
\hline & \multirow{10}{*}{$\begin{array}{l}\text { Entrepreneurial } \\
\text { Aspiration } \\
\text { Sub-index }\end{array}$} & \multirow[t]{2}{*}{ Product innovation } & New product \\
\hline & & & Technology transfer \\
\hline & & \multirow[t]{2}{*}{ Process innovation } & New technology \\
\hline & & & $\begin{array}{l}\text { Technology } \\
\text { Development }\end{array}$ \\
\hline & & \multirow[t]{2}{*}{ High growth } & Gazelle \\
\hline & & & Clustering \\
\hline & & \multirow[t]{2}{*}{ Internationalization } & Export \\
\hline & & & Connectivity \\
\hline & & \multirow[t]{2}{*}{ Risk capital } & Informal investment \\
\hline & & & Financial Institutions \\
\hline
\end{tabular}

Source Authors' own compilation

Table 3.3 shows, perhaps surprisingly, that Ireland leads, but the top ten comprise all the usual suspects in North-western Europe. This table, however, also hides significant regional variation within these countries. As Table 3.2 shows, with some interesting exceptions, the best performing entrepreneurial ecosystems in Europe are typically found in densely populated urban centers in the North and North-western parts of Europe. Stockholm, Helsinki, London, Paris, Amsterdam, and Berlin are all 


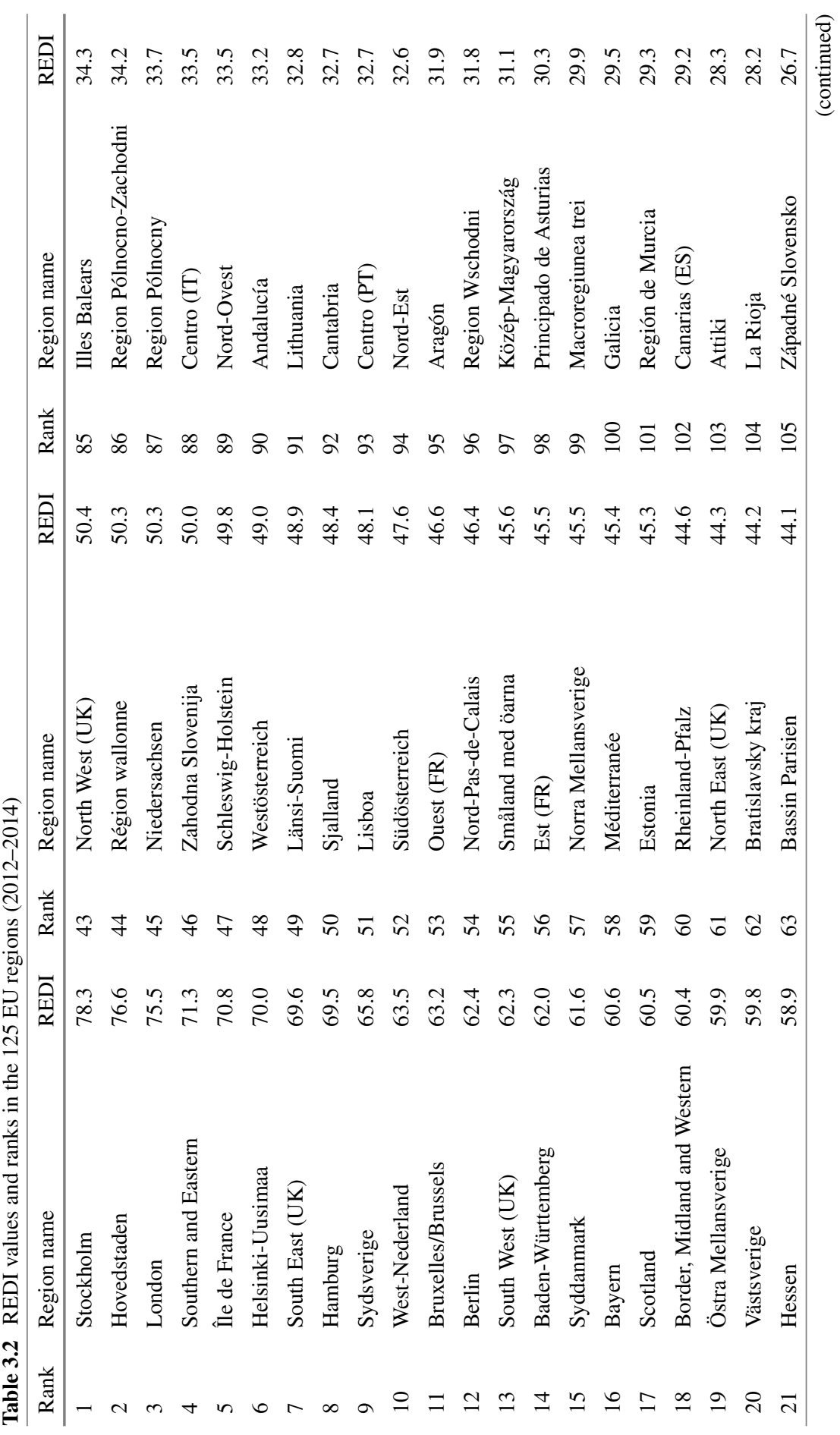




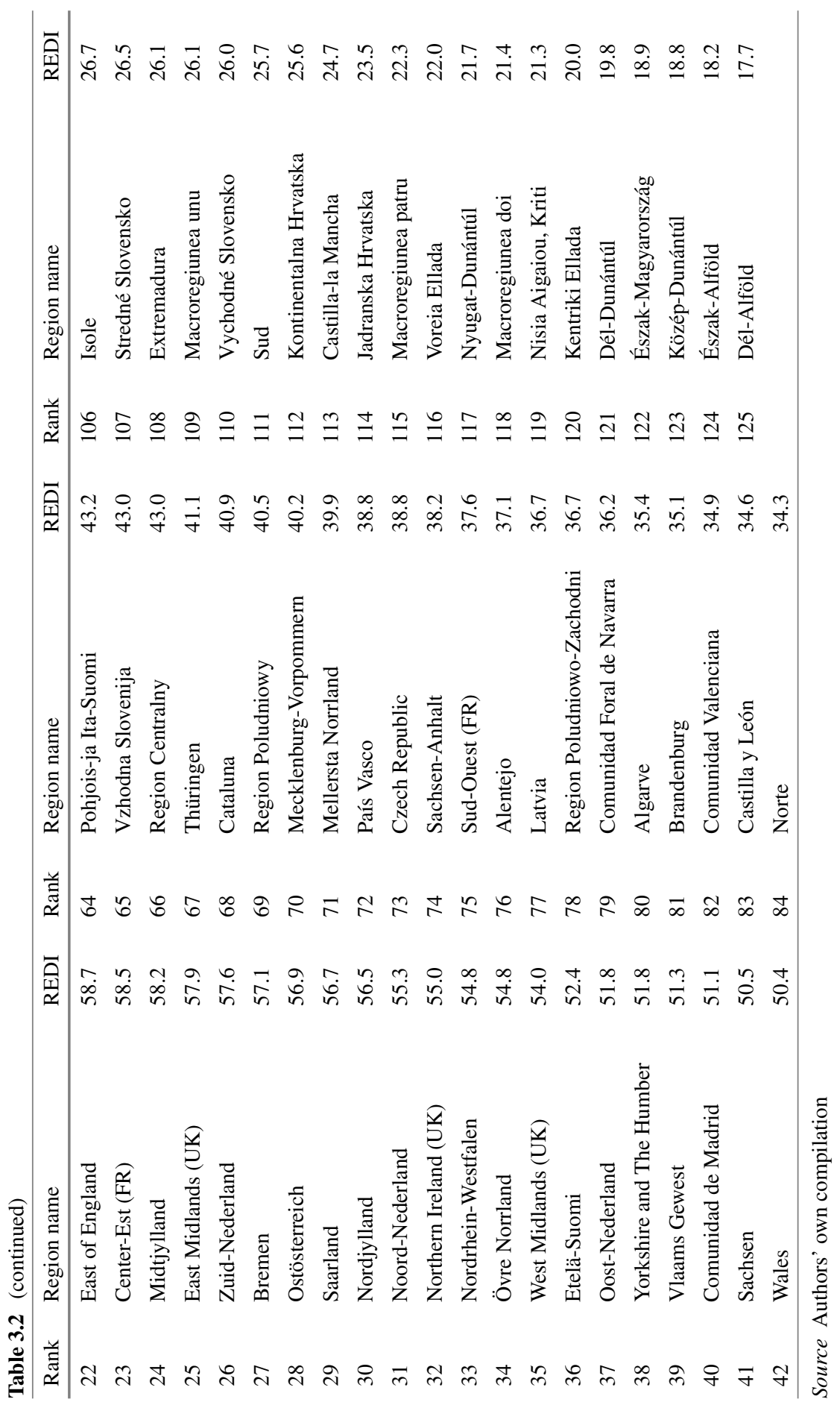


Table 3.3 Country-level REDI values and ranks in the 24 countries (2012-2014) (Based on population-weighted REDI scores)

\begin{tabular}{lll}
\hline Ranking & Country & REDI 2012-2014 average \\
\hline 1. & Ireland & 64.3 \\
2. & Denmark & 59.0 \\
3. & Sweden & 58.2 \\
4. & United Kingdom & 56.0 \\
5. & Netherlands & 56.0 \\
6. & Finland & 52.5 \\
7. & Germany & 51.1 \\
8. & Austria & 50.2 \\
9. & Belgium & 49.1 \\
10. & France & 7.6 \\
11. & Slovenia & 44.3 \\
12. & Estonia & 42.3 \\
13. & Portugal & 36.3 \\
14. & Czech Republic & 36.2 \\
15. & Poland & 34.4 \\
16. & Spain & 34.1 \\
17. & Latvia & 33.5 \\
18. & Italy & 30.0 \\
19. & Lithuania & 29.9 \\
20. & Slovakia & 25.4 \\
21. & Croatia & 23.1 \\
22. & Romania & 22.0 \\
23. & Greece & 21.8 \\
24. & Hungary & 20.7 \\
& EU average & 42.5 \\
\hline
\end{tabular}

Source Authors' own compilation

in the top ten of European regions. But the countries scoring high in Table 3.3 also have regions in the middle range of the regional ranking.

\subsection{Integrating Entrepreneurship in the GMR-Europe Policy Impact Model}

The GMR-Europe model is capable of estimating the economic impacts of entrepreneurship policy. These policies promote entrepreneurial activity which can contribute to a region's innovative capacity, eventually leading to technological and economic development. Economic impact models like the GMR-Europe are then 
able to track the widespread effects of the initial interventions. The key link through which entrepreneurship is integrated into the GMR-Europe model is the REDI introduced above. Entrepreneurship policies are assumed to affect the REDI in separate regions, while the changes in REDI set in motion the GMR-Europe model simulating the likely effects of such an exogenous improvement in the regional entrepreneurial ecosystems.

\subsubsection{General Features of GMR Models}

Models frequently applied in development policy analysis are neither geographic nor regional. They either follow the tradition of macro econometric modeling (like the HERMIN model-ESRI 2002), the tradition of macro Computable General Equilibrium (CGE) modeling (like the ECOMOD model-Bayar 2007), or the most recently developed Dynamic Stochastic General Equilibrium (DSGE) approach (QUEST III-Ratto et al. 2009). They also bear the common attribute of national-level spatial aggregation. The novel feature of the GMR approach is that it incorporates geographic effects (e.g., agglomeration, interregional trade, migration) while both macro and regional impacts of policies are simulated.

Geography plays a critical role in the effectiveness of development policies for at least four major reasons. First, interventions are implemented at a certain point in space, and their impacts might spill over to proximate locations to a considerable extent. Second, the initial impacts could be significantly amplified or reduced by short-run (static) agglomeration effects. Third, cumulative long-run processes, resulting from labor and capital migration, may further amplify or reduce the initial impacts in the region resulting in a change of the spatial structure of the economy (dynamic agglomeration effects). Fourth, as a consequence of the above effects, different spatial patterns of interventions might result in significantly different growth and convergence/divergence patterns.

"Regions" are spatial reference points in the GMR approach. They are subnational spatial units ideally at that level of geographic aggregation which is appropriate to capture proximity relations in innovation. Besides intraregional interactions, the model captures interregional connections such as knowledge flows expanding over regional borders (scientific networking or spatially mediated spillovers), interregional trade, and migration of production factors.

The "macro" level is also important when the impact of policies is modeled: fiscal and monetary policy, national regulations, or various international effects are all potentially relevant factors when calculating these impacts. As a result, the model system simulates the effects of policy interventions both at the regional and macroeconomic level. Depending on the question of interest, the macroeconomic level in the GMR-Europe model can be considered as national economies, the whole coverage of EU countries within the model, or both. With this approach, different scenarios can be compared on the basis of their impacts on economic growth and interregional convergence. 
The GMR framework is rooted in different traditions of economics (Varga 2006). While modeling the spatial patterns of knowledge flows and the role of agglomeration in knowledge transfers, it incorporates insights and methodologies developed in the geography of innovation field (e.g., Anselin et al. 1997; Varga 2000). Interregional trade and migration linkages and dynamic agglomeration effects are modeled with an empirical general equilibrium model in the tradition of new economic geography (e.g., Krugman 1991; Fujita et al. 1999). Specific macroeconomic theories are followed while modeling macro level impacts.

GMR models reflect the challenges of incorporating regional, geographic, and macroeconomic dimensions in development policy impact modeling by structuring the system around the mutual interactions of three sub-models: the Total Factor Productivity (TFP), Spatial Computable General Equilibrium (SCGE), and macroeconomic (MACRO) model blocks. Following this approach, the macroeconomic block of GMR-Europe calculates policy impacts at the aggregated (international, EU) level while the 181 NUTS2-level regional blocks provide results at the regional level.

Some policy interventions, such as changes in international trade, tax regulations, or income subsidies, can be modeled in the macroeconomic block via policy shocks affecting specific macroeconomic variables. However, many other policy instruments apply to the regional level, stimulating the regional base of economic growth such as investment support, infrastructure building, human capital development, R\&D subsidies, promotion of (intra- and interregional) knowledge flows, and entrepreneurship, which is the main focus of this chapter. These interventions are modeled in the regional model blocks and interact endogenously with the macroeconomic part. In the following sub-section, we zoom in on the mechanisms of these latter policies.

\subsubsection{GMR Model Blocks}

The GMR framework is built around three interconnected model blocks: the TFP block which is responsible for simulating changes in regional productivity levels, the SCGE block which ensures a cross-regional equilibrium and provides estimations for region-level economic variables like output and employment, and finally the MACRO block which provides the dynamics of economic variables and simulates aggregate level effects of policy interventions.

\subsubsection{The TFP Model Block}

TFP is one of the most important variables in GMR-Europe. It represents the main point through which different aspects of innovation, and innovation policy interventions in particular, interact with other parts of the model. The TFP block serves as the point in the GMR system where different driving factors behind innovation, especially entrepreneurial activity, are modeled. Then, in line with the traditions in economic modeling, the impact of these factors is implemented in the MACRO and 


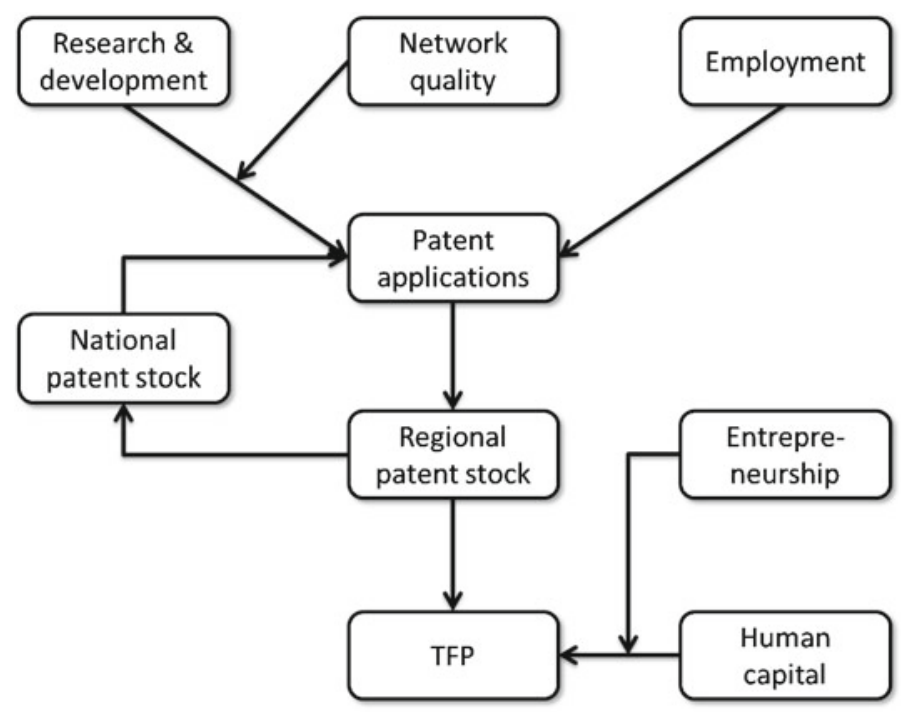

Fig. 3.1 Schematic structure of the TFP block. Source Authors' own compilation

SCGE blocks through one technology variable, generally referred to as total factor productivity, or TFP.

Figure 3.1 illustrates the setup of the TFP block in GMR-Europe. TFP is the final variable which transfers impacts generated in the TFP block over to the other parts of the model, namely the SCGE block and the MACRO block. However, the main role of the TFP block is to provide a sophisticated background for determining TFP and implement innovation-oriented policy interventions, including those targeting entrepreneurship.

The TFP block is based on the knowledge production function approach, where new knowledge, represented by patent applications in our model setup, is produced using knowledge production factors, namely R\&D efforts and labor (employment), as well as already existing knowledge which is represented by national patent stock (knowledge creation and TFP are directly modeled at the regional level). In addition to this standard approach, we also include the role of knowledge available through interregional networks, using the Ego Network Quality index (Sebestyén and Varga 2013) which is assumed to affect the productivity of R\&D in knowledge creation (better network positions lead to higher knowledge output for the same amount of inputs). New knowledge, in this case patent applications at the regional level, then feeds back into knowledge creation in a dynamic way by building up the national patent stock.

TFP is primarily linked to the regional knowledge levels in the model, but two additional forces are assumed to determine regional TFP. First, the level of human capital in the region affects TFP and second, a focal element of this setup of the GMR model, we added the entrepreneurial environment measured by REDI to the model. 
We assumed REDI to have a positive influence on TFP via enhancing the contribution of human capital to TFP. This formulation is inspired by the knowledge spillover theory of entrepreneurship (Acs et al. 2009). As entrepreneurs transfer knowledge to economic applications, a better entrepreneurial climate in a region intensifies new firm formation and helps to better exploit the knowledge embodied in human capital, which eventually leads to increasing total factor productivity. This is the point where the REDI feeds into the GMR-Europe model; productive entrepreneurship is measured by the REDI, and policy interventions that improve the entrepreneurial ecosystem are assumed to affect this variable which then sets in motion the TFP block, inducing changes in regional productivity levels as well as economic activity in the targeted region and elsewhere.

The TFP block consists of econometrically estimated equations. First, the patent equation describes how certain variables depicted in Fig. 3.1 affect regional patenting:

$$
\begin{aligned}
\log \left(\mathrm{PAT}_{t, r}\right)= & \alpha+\beta_{1} \log \left(\mathrm{PATSCKN}_{t-1, N}\right)+\beta_{2} \log \left(\mathrm{EMP}_{t-1, r}\right) \\
& +\beta_{3} \log \left(\mathrm{RD}_{-} \mathrm{TOTAL}_{t-1, r}\right) \\
& +\beta_{4} \log \left(\mathrm{RD}_{-} \mathrm{TOTAL}_{t-1, r}\right) \log \left(\mathrm{ENQFP}_{t-1, r}\right)+\varepsilon_{t, r}^{\mathrm{PAT}}
\end{aligned}
$$

Patents on the left-hand side are measured by EPO patent applications (PAT), national patent stock is the cumulative number of patents at the country level (PATSCKN), research and development efforts are proxied with R\&D expenditures (RD_TOTAL), employment is captured by the total level of employment in the region (EMP), and network quality is measured with the ENQ index (Sebestyén and Varga 2013), calculated over the network of Framework Program partnerships between regions (ENQFP). The patent equation (Eq. 3.1) potentially contains endogeneity through network formation, employment, and R\&D as these factors may be shaped by patenting in a region just as well as shaping it. We designed the equations with a one period (year) lag in order to overcome this problem to a certain extent.

Second, the TFP equation describes how certain variables (as shown in Fig. 3.1) affect regional productivity:

$$
\begin{aligned}
\log \left(\mathrm{TFP}_{t, r}\right)= & \alpha+\beta_{1} \log \left(\mathrm{PATSCKR}_{t-1, r}\right)+\beta_{2} \log \left(\mathrm{HUMCAP}_{t-1, r}\right) \\
& +\beta_{3} \log \left(\mathrm{HUMCAP}_{t-1, r}\right) \mathrm{REDI}_{t-1, r}+\varepsilon_{t, r}^{\mathrm{TFP}}
\end{aligned}
$$

In this equation, accumulated knowledge is measured by the cumulative number of patents in the region (PATSCKR), while the level of human capital at the regional level is proxied by the population (between age 25 and 64) with tertiary education attainment (HUMCAP). To model the influence of entrepreneurship on TFP, human capital interacts with the quality of the entrepreneurial ecosystem in the equation. ${ }^{2}$

\footnotetext{
${ }^{2}$ It could be argued that a reasonable alternative of the TFP equation would be a specification where REDI interacts with the regional patent stock. However, there is a very important distinction between the two forms of knowledge (human capital and accumulated knowledge stock) in the Romerian knowledge production function framework, and this distinction is followed in our specifications
} 
The quality of the entrepreneurial ecosystem is measured by the REDI. ${ }^{3}$ The TFP on the left-hand side is estimated using a standard production function approach with capital and labor.

After estimating the two equations of the TFP block, we have a system of equations which is able to simulate the effects of different interventions affecting research and development, human capital, networking, or the entrepreneurial climate on regional TFP. One drawback of this system is that the estimated coefficients which drive these impacts are common across all regions in the model, reflecting average tendencies in the sample of regions. However, one may argue that due to the large differences in the development level as well as the sociocultural and institutional context of European regions, mechanisms through which different interventions affect regional productivities differ largely across regions. We control for these differences in two ways. First, in both equations, the interaction terms render the respective marginal effects of R\&D, human capital, network quality, and entrepreneurship development level region-specific. Second, we augment this heterogeneity with a specific calibration process through which region-specific parameters are calculated through an optimization process to improve model fit. This second method is discussed briefly below.

Given the observed data, we fit linear trends on these data points for all variables, except regional and national patent stocks (the former is directly given by the patent equation and the latter is calculated by summing up regional patent stocks in every period). After trend fitting, we extrapolate the trend for out-of-sample years. These trends constitute the baseline of the TFP block. After extrapolating trend values for all variables in the TFP block, we perform the regressions on these data points as well. Coefficients estimated on the historical data and coefficients estimated on the trend data closely approximate each other.

The coefficients estimated on the trend data constitute the basis of region-specific parameter calibrations in the next step. The aim of the calibration is to find regionspecific values for selected parameters, which improve the overall fit of the model. After a careful selection procedure among several model versions, three coefficients of the TFP block, namely the constant term and the coefficient of employment in the patent equation (parameters $\alpha$ and $\beta_{2}$ ) and the constant term in the TFP equation

of the equations in the TFP block (Romer 1990). The stock of patents represents accumulated knowledge that is available in the region for potential economic applications, whereas human capital refers to knowledge which is actually present in the region being embodied in qualified labor. Therefore, the stock of knowledge plays a passive role in technology development, whereas human capital is the one that contributes actively to regional productivity improvements. In our formulation of the TFP equation, this role is enhanced by the quality of the regional entrepreneurial ecosystem. With a higher quality of this ecosystem, the same level of human capital contributes to a more intensive increase in TFP via more active involvement of human capital in new firm formation. ${ }^{3}$ As described in Sect. 3.2, the REDI is a complex index that accounts for several features of the entrepreneurial ecosystem. Due to this complexity, some of the variables that appear in the GMR model also play a role in the REDI. However, these variables are interactive with several others, and throughout the pillar system, the correlation of the REDI super-index with any single component variable is small. 
(parameter $\alpha$ ), are calibrated. ${ }^{4}$ As a result of this calibration process, we are presented with region-specific parameter values for the listed three parameters of the TFP block which improve the fit of the TFP block equations and retain the average tendencies represented by the trend-based estimation. In this way, we obtain region-specific mechanisms built in the TFP block with respect to the effects of right-hand side variables on patenting activity and the productivity of the regions.

\subsubsection{The SCGE Model Block ${ }^{5}$}

The SCGE model block draws on regional productivity changes and then simulates the likely impacts of these changes on regional economic variables like output, prices, wages, and employment. SCGE models add the spatial dimension to the (usually a-spatial) CGE models. Economic units are regions, which are interconnected by trade flows and migration. The most important feature of this block is that it takes into account interactions across regions through the trade of goods and services as well as the mobility of production factors. Also, transportation costs are explicitly accounted for and positive and/or negative agglomeration effects are also part of the model structure.

The model distinguishes between short-run and long-run equilibria. In the short run, markets are in equilibrium within and across all regions. However, this does not necessarily mean that the whole regional system has reached a balanced situation. In the long run, differences in utility levels across regions induce labor migration, followed by the migration of capital, leading to a long-run spatial equilibrium where interregional utility differences are eliminated. Although possible in principle, this equilibrium is hardly reached within the applied simulation horizon, leaving considerable gaps in utility levels in the simulated outcomes.

\subsubsection{The MACRO Model Block}

The macroeconomic block of the GMR approach serves two purposes. First, this is the point, where aggregate relationships and policies, such as exchange rate toward the rest of the world, inflation, monetary, and fiscal policy, can be handled. Second,

\footnotetext{
${ }^{4}$ This results in an optimization procedure where the objective function is the sum of the following five elements: (1) Mean average percentage error of the regional patent application variable (average percentage deviation of simulated $\mathrm{PAT}_{i, t}$ values from the trend values). (2) Mean average percentage error of the TFP variable (average percentage deviation of simulated $\mathrm{TFP}_{i, t}$ values from the trend values). (3) Mean average percentage error of the average calibrated region-specific constant terms in the patent equation (average percentage deviation of calibrated constant terms from the trend-based estimated values). (4) Mean average percentage error of the average calibrated region-specific coefficient of employment in the patent equation (average percentage deviation of calibrated coefficients from the trend-based estimated values). (5) Mean average percentage error of the average calibrated region-specific constant terms in the TFP equation (average percentage deviation of calibrated constant terms from the trend-based estimated values).

${ }^{5}$ This section reiterates a short passage that was published in Varga et al. (2018).
} 
it provides dynamics to the otherwise static SCGE block. In the latter, regional productivity, labor, and capital stocks are exogenous. The TFP block provides the dynamics of regional productivity levels, but in order to account for the possible employment and investment effects of the simulated policies, we need to provide dynamics for labor and capital stocks of the regions. This is performed by the MACRO block, which provides an aggregate estimation of the likely employment and capital stock impacts of the simulated policies, and are then broken down to the regions in function of the regional productivity growth rates.

The macroeconomic block of GMR-Europe calculates policy impacts at the EU and national level while the 181-region NUTS2-level TFP and SCGE blocks provide results at the regional level. The model calculates the policy impacts on various economic variables such as GDP, employment, investment, prices at the regional, national, and aggregate European levels.

The macroeconomic block is a standard, large-scale Dynamic, Stochastic, General Equilibrium (DSGE) model. We apply the QUEST III model developed by the European Commission for the Euro area and re-estimated it with additional countries to cover the same set of regions as those represented in the other two model blocks. Therefore, the set of countries include the Euro-countries and some Eastern European countries that are not part of the monetary union. The description of the original model can be found in Ratto et al. (2009), while the re-estimated version is described in Varga et al. (2018).

\subsubsection{Impact Mechanisms in the GMR Model}

The three mutually connected model blocks are depicted in Fig. 3.2. Without interventions, the TFP growth rate is assumed to follow an exogenous and identical steady state growth rate in every region, and the economy grows on a balanced growth path primarily driven by the MACRO block. If any exogenous shocks are fed into the model, it leaves this balanced growth path, and we can examine how the policy-induced shocks affect the path of the economy compared to the steady state path.

Given its setup, the GMR-Europe model is able to handle several types of policy interventions, as shown on the left-hand side of Fig. 3.2. Different macroeconomic policies, such as inflation targeting, other aspects of monetary policy, general fiscal expansion, and different tax-related policies, are applied at the macro level, directly affecting the MACRO block, while their effects spill over to other model parts as well. Other policies apply at the regional level. These may include investment support or public infrastructure development, which directly affects the (private or public) capital stock in specific regions. Through the interconnected model setup, these interventions then affect economic activity in other regions as well. Finally, there are policies which directly affect the TFP block. These are interventions which have an effect on regional productivity, like supporting education, $R \& D$, network formation, 


\begin{tabular}{|c|c|c|}
\hline Interventions & $\begin{array}{c}\text { Spatio-temporal } \\
\text { dynamic }\end{array}$ & Impacts \\
\hline
\end{tabular}

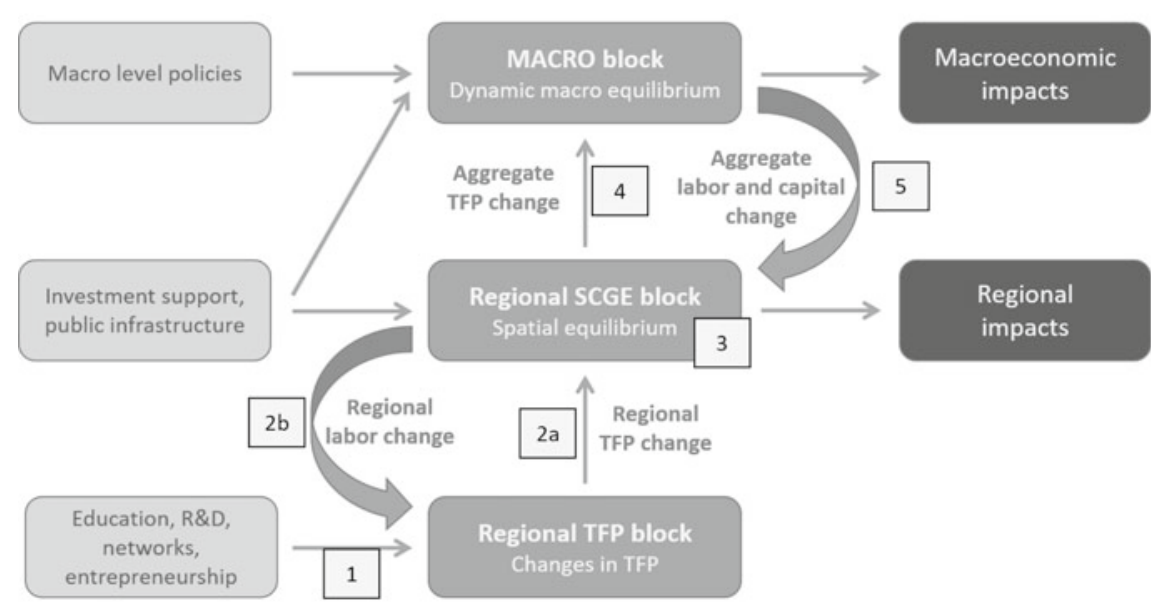

Fig. 3.2 Regional and macroeconomic impacts of the main policy variables in the GMR-Europe model. Numbers refer to the steps of the impact mechanism of policy interventions. Source Authors' own compilation

or entrepreneurial activity. These interventions affect regional TFP as described in Fig. 3.1, and then these effects spill over to other parts of the model.

As the present chapter focuses on policy interventions related to entrepreneurial activity, we provide a more detailed account of the policies affecting regional TFP. The following steps, augmented by the numbers in Fig. 3.2, help keeping track of the adjustment process initiated by policy interventions targeting entrepreneurship, R\&D, education, or network formation, all affecting regional TFP in the first place.

1. Resulting from $R \& D$, entrepreneurship- and network-related interventions as well as human capital and physical infrastructure investments (which increase public capital and eventually impact the level of TPF as well), regional Total Factor Productivity changes/increases (link 1 in the figure);

2. Changing TFP induces changes in quantities and prices of output and production factors in the short run (link 2a) while in the long run (following the mechanisms described above) the impact on in-migration of production factors implies further changes in TFP not only in the region where the interventions happen but also in regions which are connected by trade and factor migration (link $2 b$ );

3. Induced by the increasing productivity, private investments increase expanding regional private capital which causes further changes in regional variables (output, prices, wages, prices, TFP, etc.) in the SCGE model block. The impact of private investment support affects the MACRO model also via increased private capital (link 3, within the SCGE block); 
4. For every year, changes in TFP are aggregated to the national level, which increases TFP in the MACRO model as time-specific shocks (link 4). The macroeconomic model calculates the changes in all affected variables at the national level;

5. Changes in employment and investment calculated in the MACRO block are distributed over the regions following the spatial pattern of TFP impacts (link 5);

6. The SCGE model runs again with the new employment and capital values to calculate short-run and long-run equilibrium values of the affected variables (links 3, 2a, and $2 \mathrm{~b}$ are used again);

7. The process described in steps 5 and 6 continues until aggregate values of regional variables calculated in the SCGE model get sufficiently close (less than $10^{-10}$ percentage deviation) to their corresponding values calculated in the MACRO model. This solution ensures consistent simulation results across the different model blocks. Also, our experience shows that convergence is always achieved and within a very limited number of iterations.

\subsection{Policy Simulations}

The following simulations illustrate the potential use of the GMR-Europe model in evaluating reforms which aim to strengthen the entrepreneurial society. In principle, it would be possible to simulate the effects of a differentiated and tailored strategy to improve regional entrepreneurial ecosystems as, for example, presented in Chaps. 57 in this volume (Sanders et al. 2020a, b, c). In this chapter, the aim is to illustrate how our model setup works, and we therefore focus on how a common shock to the REDI score would be transmitted in the GMR framework. Results show that there are differences in the extent to which an equi-proportional increase in the REDI scores affects regional productivities. Moreover, the dynamic feedback mechanisms within the model generate diverse paths for regional output levels in response to such a shock.

\subsubsection{Simulation Setup}

In the simulation presented below, we track the effects of an exogenous increase in the REDI in all regions. More formally, we follow the strategy below:

1. We take the baseline REDI scores of the model. The base year is 2012, and the baseline of the TFP block goes along empirically fitted trends from 2012 to 2031, which means that in the baseline model runs, the REDI score of every region proceeds along a trend line derived from the observed data; 
2. For every region, we then calculate the average of the baseline REDI scores over the simulation years (2012-2031) and define 1\% of these average scores as a policy intervention (technically an exogenous shock to the model);

3. This $1 \%$ improvement is applied to the REDI in every region in a way that the REDI is increased from its baseline value to a 5\% higher value through the first 5 years of the simulation (2012-2016). Note that after five years the value of the REDI does not change meaning that the annual improvements in REDI result in a permanent positive effect on the quality of EE in every NUTS2 region;

4. Every region receives this $1 \%$ annual improvement in the REDI, and we trace their effect on regional TFP and GDP levels as well as aggregate country-level versions of these variables.

Of course, focusing on the REDI provides a bird-eye view on entrepreneurial policies. We can interpret the idea behind these simulations as follows: What is the economic impact of a five percent improvement of the entrepreneurial climate/ecosystem in each region over a five-year period? We use this counterfactual simulation as a first approximation and for illustrative purposes, but emphasize that the detailed structure of the REDI allows the model to account for more detailed approaches in this respect. Overall, these simulations reflect the potential effects of policies which are capable of improving the entrepreneurial ecosystem of a region by adjusting either of the pillars behind the REDI. It is important to underline that the equality of the shocks (in percentage terms) implies regional divergence in our simulations. The impact of a REDI shock depends most importantly on the size of the REDI (i.e., the development level of the regional entrepreneurial ecosystem) and on the size of human capital in the region. Therefore, many highly entrepreneurial regions with strong human capital gain more from the shock than their less developed counterparts. One should realize that the same percentage increase in the REDI score cannot be the consequence of regionally balanced policy interventions, and, indeed, the improvement of the quality of the ecosystem in more entrepreneurial places probably requires more effort than in less developed regions.

\subsubsection{Simulation Results}

Although the model is capable of tracking many regional and aggregate level variables, we focus on the effect of the REDI improvement on total factor productivity (TFP) and GDP. In both cases, we present the percentage deviation of the simulated TFP/GDP values after the applied interventions from their baseline levels. As a result, the diagrams reflect the percentage impact of these policies, or, to what extent would TFP and GDP be higher/lower as a result of the policy intervention, compared to the no intervention (business as usual) case.

In Fig. 3.3, we summarize the country-level results of the simulations. On the left-hand side, the country-level impacts are shown for TFP, while on the righthand side the time averages of the GDP impacts are depicted for countries. The 

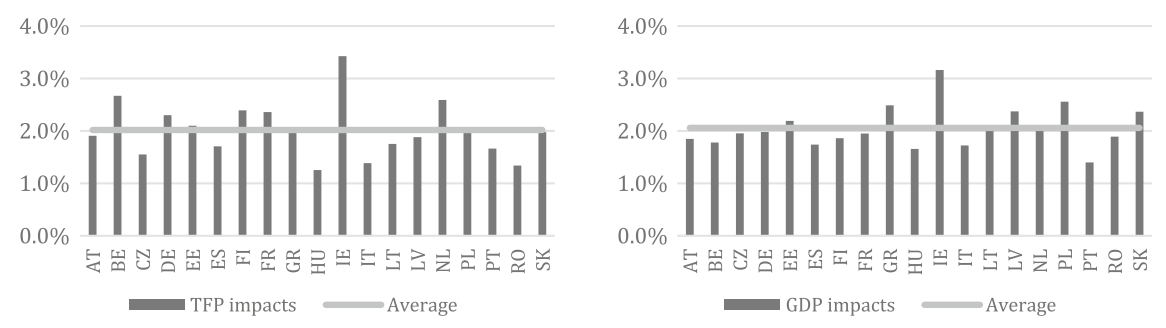

Fig. 3.3 Country-level impacts of $1 \%$ annual shocks over a five-year period to REDI on TFP and GDP. Source Authors' own compilation

horizontal lines show the EU-average impacts. The graphic shows that a $1 \%$ annual improvement in the entrepreneurial climate over 5 years in every region leads to a $2 \%$ increase in TFP and productivity on average (EU level). The GDP impact is slightly higher, but the productivity and GDP effects go hand in hand. This is not surprising, as in the simulations, the shock has its effect through enhancing regional productivity. Figure 3.3 also shows that the positive development in the entrepreneurial environment of regions positively affects the productivity levels in all countries. However, there are differences in the magnitude of this effect. While Ireland benefits the most from this policy, Hungary seems to be performing worst in this respect. This corresponds with the initial ranking of regions and countries in Tables 3.2 and 3.3.

In the dynamic analysis of policy impacts, we zoom in on the mechanisms in the case of four countries representing the four types of capitalism: Ireland (a Liberal Market Economy), Germany (a Coordinated Market Economy), Hungary (an Eastern Market Economy), and Italy (a Mediterranean Market Economy). Although, GDP impacts follow the TFP impacts quite closely, as seen from Fig. 3.4, there are considerable qualitative differences in the time path of the effects. In some countries, although the overall effect of the policy is positive, after the "lifting" power of the policy (first 5 years) phases out, the impacts tend to decrease compared to the peak year. This effect is due to the complex mechanisms within the GMR model where
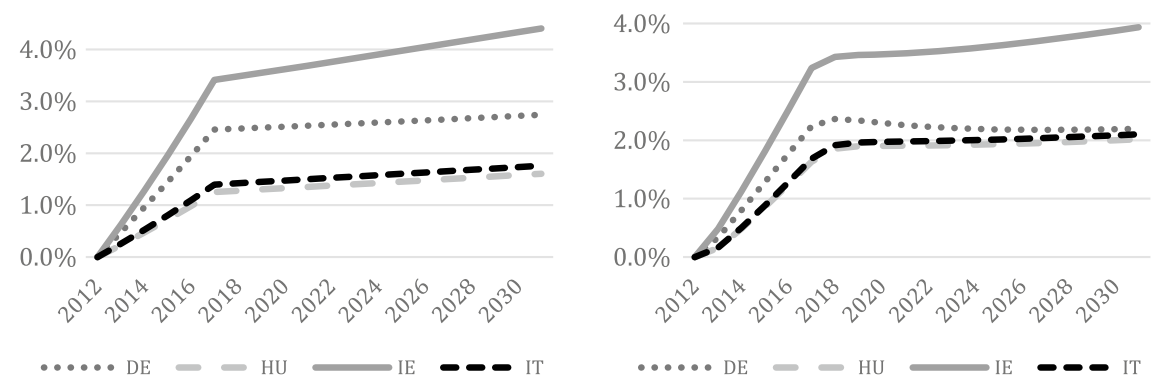

Fig. 3.4 Dynamics of impacts of annual $1 \%$ shocks over a five-year period to REDI on TFP and GDP in the selected countries. Source Authors' own compilation 
productivity growth and the resulting economic development affect and feed back to that of other regions through trade and factor mobility. These feedback mechanisms may result in out-migration or capital flight which negatively affects the growth of some regions.

In order to better understand the impact mechanism behind these results, it is useful to distinguish all steps of the mechanism. First, the impact of the initial REDI improvement has a one-year lag on TFP and GDP changes. Thus, interventions between 2012 and 2016 have direct productivity and economic effects between 2013 and 2017. Second, the initial level of entrepreneurship is a defining factor in the changes in productivity since the same increase of the REDI index in entrepreneurially developed regions means a much higher absolute change in the REDI and a similarly higher productivity change as a consequence. Third, the direct short-run GDP and TFP impacts are heavily dependent on the level of human capital endowment in regions. Regions with higher levels of human capital are capable of taking more productivity and economic advantage from a higher-quality entrepreneurial ecosystem. If the levels of entrepreneurship and human capital stock are large in a region, the short-run economic impacts are large as well. In Fig. 3.4, this means that the slope of the curves is higher than the EU average during the 5 years of the interventions. Fourth, some other aspects, such as investment, have to be considered in the long run. The direct impacts of REDI last until 2017 since after 2016 there is no further improvement in the entrepreneurial ecosystem. However, economic impacts are still observed in years that follow. We especially experience further increase of growth in 2018. This indirect impact is caused by the increased capital stock due to the additional investment that is possible as a result of increased income and saving caused by the positive effects of entrepreneurship development policy, since there is a two-year time lag between REDI changes and the effects of investment decisions. As a result of improvements in the entrepreneurial ecosystem, income changes in the next period and as a result of this change in income investment will increase, resulting in a larger capital stock available for production two years later. Finally, human capital accumulation also affects the results in the long run (after the interventions), as it follows different trends in the regions.

After 2018, the path of GDP and TFP changes less rapidly. In many countries, these paths are stabilizing to a long-run growth path. However, some countries are able to further increase their growth rate even in the long run, while others lose some of the initial gains of entrepreneurship policy. The long-run growth paths are influenced by many factors, but productivity is still a key variable in this process which is heavily influenced by the changes in human capital stock. Countries that are characterized by a high rate of human capital accumulation can grow faster in the long run than the average. In contrast, low human capital accumulation reduces the growth rate in the long run, and those countries might face a slowing growth path. These effects are further influenced by interregional migration and changes in trade as well.

In addition, the interplay between the growth and substitution effects of TFP improvement might play a role in regional GDP impacts. In cases when demand for output does not increase, firms might use less inputs resulting from productivity 
improvement. As a result of that some regions might lose some of their employment in the long run. Thus, even if a region experiences an improvement in TFP, it does not necessarily mean that the region will grow faster than others with less impressive TFP growth.

As shown in Fig. 3.4, Ireland is capable of benefitting most from the REDI improvements, in terms of TFP and GDP. Ireland is characterized by the highest level of REDI among the countries in the model, thus in absolute terms, the Irish shock will be the largest as well. This is accompanied by a relatively high level (significantly higher than average) of human capital. These two factors and the description of the impact mechanism above can explain why Ireland's TFP and GDP increase so much under the five years of the intervention. In the long run, Ireland has one of the highest rates of human capital accumulation, which drives the long-run impacts after the interventions. All these factors contribute to the predicted success of entrepreneurship development policy in Ireland.

Germany also gains much from the improvement of the REDI scores. The initial levels of REDI and human capital are somewhat smaller than in case of Ireland. Thus the growth of productivity and GDP under the first 5 years is lower but still above the other two less developed countries. In the long run, we have shown that human capital accumulation drives economic growth. The German path clearly illustrates that slow human capital accumulation is not enough to maintain the initial economic impacts of the shock.

At the same time, Italy and Hungary have similar, lower-level growth paths. Although Italy has a higher level of initial REDI, this advantage is partially compensated by the higher average regional human capital stock in Hungary. As a consequence, in the first five years, Italy grows only slightly faster than Hungary. In the long run, both the Hungarian and Italian paths approach the German growth path due to the higher level of human capital accumulation. Again, the Italian accumulation is slightly higher than the Hungarian one, so a small gap can be found in the long-run economic development paths of these countries.

Migration also contributes to the determination of these growth paths. While Germany is capable of attracting new labor force in the short run due to its high growth potential in the first five years, Hungary and Italy lose some of their labor forces. This effect, however, is weakened significantly in the long run when the German growth advantage disappears, and Hungary and Italy catch up. As mentioned before, Ireland has the highest level of capital accumulation, thus economic and productivity impacts are further increased in the long run which, as a consequence, generates more immigration strengthening the positive effects.

At the regional level, the same impact mechanism drives the economic effects, but in that case the differences are more pronounced since the national impacts can be interpreted as a weighted average of the regional effects. Thus, by looking at the regional impacts, one can have a much more detailed picture of the spatial effects of entrepreneurship policies. Figure 3.5 shows the regional breakdown of the simulated impacts. As can be seen, GDP impacts (on the right-hand side) follow the productivity impacts (on the left-hand side), but there are considerable differences between regions. In most of the cases, we see that central, more developed regions 

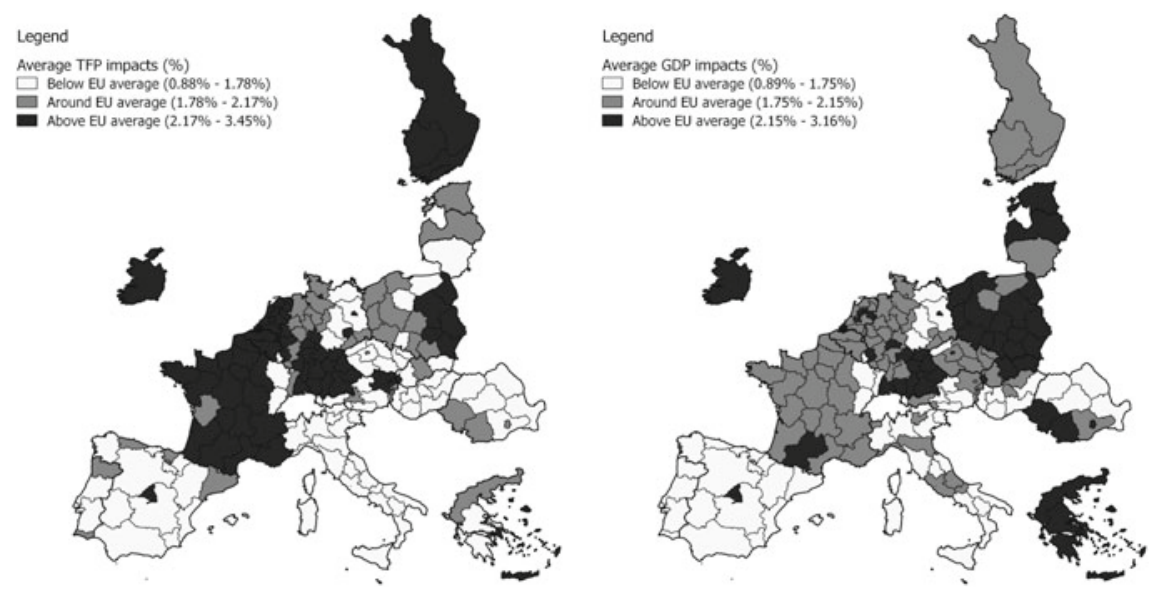

Fig. 3.5 Regional impacts of $1 \%$ annual REDI shocks over a five-year period on regional TFP and GDP levels. Source Authors' own compilation

(Ireland, southern Germany, northern regions, capital cities, French regions) gain more from the improvement in REDI. The complex interaction mechanisms in the GMR model are visible at the regional level, marked by significant differences in regional impacts and especially in favor of central regions. Due to their economic weight, these regions are able to attract production factors in the long run, eventually implying improvements in less developed regions. However, we can also see that in the long run, improving the entrepreneurial ecosystem can be successful in less developed regions, as some Polish, Greek, and some parts of Romania are able to catch up.

Turning our attention to the regions of the four selected countries, we can identify strong regional differences in the effectiveness of entrepreneurship policies. First, since Ireland consists only of one region in our model, we cannot give a more detailed analysis of spatial economic impacts. As described previously, entrepreneurship policy is extremely effective in Ireland both in the short and the long run.

In Germany, we see that the less developed, eastern part gains the least in economic and productivity improvement. This is due to the fact that the majority of these regions are characterized by low initial REDI scores and low human capital accumulation. Even in the slowly growing areas, central places like Berlin are capable of growing around the EU average thanks to the concentration of human capital and entrepreneurial activities (REDI).

The southern, more developed part of the country is mainly characterized by a developed entrepreneurship ecosystem (high REDI) and with some variation, and exceptions, the majority of regions has high level and accumulation of human capital (in some regions only one of these factors are given), which makes them very successful in terms of economic impacts. However, some regions are not able to translate all of the productivity changes into GDP growth since other factors play a significant 
role. For example, in Stuttgart, productivity improvements might substitute for labor which can mitigate the growth potential to some extent.

Regions in the countries located in the East of the EU are more diverse. In general, they all excel at some determining factors of the policy, but they do not excel in all of them which means that they are not able to generate exceptionally high productivity and economic growth. In some cases, judging the factors behind regional growth changes can be straightforward since all the influencing factors contribute to growth in the same direction. In Hungary, which has a highly concentrated spatial structure, Budapest is characterized by the highest level of both human capital and REDI. As a consequence, this region is the most potent in terms of the short-run impacts. In the long run, both human capital accumulation and the substitution effect must be considered. In the case of Budapest, accumulation is also the highest in the country which increases the growth path of Budapest in the long run. This growth is only slightly reduced by the substitution effect described above. Still our result suggests that the TFP effect is slightly below the EU average, while the GDP effect is around the EU average. Outside the capital, however, due to the lack of foundations, we see only limited potential of entrepreneurial development policies.

Finally, Italy has a traditionally divided spatial economic structure. We find again that the core regions can benefit the most from entrepreneurial policies. This concerns mainly northern Italian regions (like Lombardy and the capital with some neighboring regions). If we look behind these results, we can state that northern, developed regions benefit from both the high level of human capital and entrepreneurship, while regions around the capital are less developed in terms of entrepreneurship, but still concentrate a high stock of human capital. Compared to EU averages, however, these nationally high values are not high enough to provide the basis for significant economic growth at the EU level. Our simulations also show that southern regions that are far from the capital have a low chance of benefitting significantly from these policies due to their low level of development, both in terms of entrepreneurship and human capital.

\subsection{Conclusions}

Policy interventions and their impacts have always been in the center of interest. Over the decades, economists have developed various tools to estimate the ex-ante impact as well as to evaluate the ex-post effects of policy interventions. Simple econometric regression models are able to test the significance of a policy instrument based on the ceteris paribus assumption. However, these uniform suggestions neglect the likely diverse effects of policy interventions as well as the potential complex impact of a particular policy element on other influential factors. Simultaneous regressions could handle the complex effect of closely related factors. However, the one-size-fits-all policy recommendations remain an open issue.

Many entrepreneurship scholars believe that improving the entrepreneurial ecosystem contributes positively to economic growth, development, job creation, and 
productivity. However, empirical studies report contradicting impacts depending on the definition of entrepreneurship, the level of development, the unit of analysis, and modeling strategy, just to mention the most important factors. Most of these studies rely on regression-based methodologies by assuming a universal and homogenous impact of entrepreneurship policies. In this chapter, we used the REDI to simulate the impact of improving the entrepreneurship ecosystem of regions in 24 countries of the European Union. REDI is a composite indicator that combines the individual and the institutional factors of entrepreneurship into fourteen pillars and three sub-indices. Two analytical tools, the average equalization and the penalty for bottleneck techniques serve to identify region-based bottlenecks in the entrepreneurial ecosystem.

We have incorporated REDI into the recently extended GMR-Europe model to test the effects of improving the entrepreneurial ecosystem on TFP and GDP levels. Unlike regression-based methods, GMR-Europe builds on spatial patterns of dynamic agglomeration and spillover effects. GMR-Europe has three parts, the Total Factor Productivity (TFP), the Spatial Computable General Equilibrium (SCGE), and the macroeconomic (MACRO) model blocks. REDI, our measure for entrepreneurial ecosystem quality, is the part of the TFP block influencing regional productivity through interaction with human capital. The TFP block is able to simulate region-specific impacts of policy interventions like R\&D support, development in human capital, entrepreneurship, or innovation networks on regional productivity. The macroeconomic block calculates policy impacts at the overall EU and national levels, while the 181-region NUTS2-level TFP and SCGE blocks provide results at the regional level. The model calculates the impact on various economic variables such as GDP, employment or prices at the regional, national, and aggregate European levels.

This chapter zoomed in on the impacts of improving the entrepreneurial ecosystem at the regional level. Our simulations were based on a $1 \%$ annual improvement of the REDI score in every region over a five-year period. The impacts of these improvements were tracked on regional and aggregate TFP and GDP levels. On average, a $1 \%$ annual improvement over the five-year period leads to an average $2 \%$ increase both in GDP and in TFP, while GDP impact is slightly larger. However, the magnitude of the impact varies significantly across countries while regional impacts are even more dispersed. In part because of the way we set up our simulation, but these differences are also due to the complex mechanisms within the GMR model where productivity growth and the resulting economic development affect and feed back to other regions through trade and factor mobility. These feedback mechanisms may result in out-migration or capital outflows that can have negative effects on the growth of some regions. Our simulation results suggest that it is the more developed, central regions that benefit the most from REDI improvements, such as policy interventions targeting the entrepreneurial ecosystem.

Like any other simulation exercise, our analysis has its limitations. First, we have not yet explored the full richness of the REDI in our simulation. To illustrate how policy analysis could work with the combination of REDI and GMR modeling, we chose to implement a uniform exogenous $1 \%$ annual shock to REDI in all regions. Future 
research could easily go into more detail and simulate more specific and realistic interventions. REDI-based policy recommendations are built on the so-called system failure improvement that is an analogy to classical public policy aiming to correct market failures. That is, policymakers could target policies at improving the weakest link in the regional ecosystem, giving them endogenous REDI improvements that can then be simulated as was shown. In Chaps. 5-7 in this volume (Sanders et al. 2020a, b, c), we illustrate how REDI can be used to diagnose and inform a reform strategy for Italy, Germany, and the UK, respectively. The GMR simulations in this chapter have shown that such tailored reforms are likely to cause heterogeneous effects across regions. A limitation of the REDI is that the interventions that can be studied under the proposed framework remain limited to those that affect aspects of the ecosystem represented in the REDI. We believe the processes and mechanisms in the GMR are important to consider, and the present model setup can generate testable hypotheses. Future research could rigorously and empirically test the assumed structures and specifications in the REDI-extended GMR model.

\section{Appendix: The REDI Calculation Method}

In constructing the index, we followed eight steps:

1. The selection of variables: We start with the variables that come directly from the original sources for each region involved in the analysis. The variables can be at the individual level (personal or business) that are coming from the GEM Adult Population Survey or the institutional/environmental level that are coming from various other sources. Altogether, we have data for a mix of 125 NUTS1 and NUTS2 regions.

2. The construction of the pillars: We calculate all pillars from the variables using the interaction variable method, that is, by multiplying the individual variable with the proper institutional variable. This results in pillar values for all the 125 EU regions.

$$
z_{i, j}=\mathrm{IND}_{i, j} * \mathrm{INS}_{i, j}
$$

for all $j=1, \ldots, k$, the number of individual and institutional variables

$\mathrm{IND}_{i, j}$ is the original score value for region $i$ and variable $j$ individual variable

$\mathrm{INS}_{i, j}$ is the original score value for region $i$ and variable $j$ institutional variable $z_{i, j}$ is the original pillar value for region $i$ and pillar $j$.

3. Normalization: Pillars values were first normalized to a range from 0 to 1 by using the distance methodology:

$$
x_{i, j}=\frac{z_{i, j}}{\max z_{i, j}}
$$


for all $j=1, \ldots, k$, the number of pillars

where $x_{i, j}$ is the normalized score value for region $i$ and pillar $j$

$z_{i, j}$ is the pillar value for region $i$ and pillar $j$

$\max z_{i, j}$ is the maximum value for pillar $j$.

4. Capping: All index building is based on a benchmarking principle. In our case, we selected the 95-percentile score adjustment meaning that any observed values higher than the 95-percentile are lowered to the 95-percentile.

5. Average pillar adjustment: The different averages of the normalized values of the pillars imply that reaching the same pillar values requires different efforts and inputs. Since we want to apply REDI for public policy purposes, the additional inputs for the marginal improvement of the pillar values should be the same for all pillars. Therefore, we need a transformation to equalize the average values of the components. Equation 3.5 shows the calculation of the average value of pillar:

$$
\overleftarrow{x}_{j}=\frac{\sum_{i=1}^{n} x_{i, j}}{n}
$$

We want to transform the $x_{i, j}$ values such that the potential minimum value is 0 and the maximum value is 1 :

$$
y_{i, j}=x_{i, j}^{k}
$$

where $k$ is the "strength of adjustment," the $k$ th moment of $X_{j}$ is exactly the needed average, $\bar{y}_{j}$. We have to find the root of the following equation for

$$
\sum_{i=1}^{n} x_{i, j}^{k}-n \bar{y}_{j}=0
$$

It can be seen, based on previous conditions and derivatives, that the function is decreasing and convex, meaning it can be quickly solved using the wellknown Newton-Raphson method with an initial guess of 0 . After obtaining $k$, the computations are straightforward. Note that if

$$
\begin{aligned}
& \bar{x}_{j}<\bar{y}_{j} k<1 \\
& \bar{x}_{j}=\bar{y}_{j} k=1 \\
& \bar{x}_{j}>\bar{y}_{j} k>1
\end{aligned}
$$

that is $k$ be thought of as the strength (and direction) of adjustment.

6. Penalizing: After these transformations, the penalty for bottleneck (PFB) methodology was used to create pillar adjusted PFB values. We define our penalty function as follows: 


$$
h_{(i), j}=\min y_{(i), j}+\left(1-\mathrm{e}^{-\left(y_{(i) j}-\min y_{(i), j}\right)}\right)
$$

where $h_{i, j}$ is the modified, post-penalty value of pillar $j$ in region $i$ $y_{i, j}$ is the normalized value of index component $j$ in region $i$

$y_{\min }$ is the lowest value of $y_{i, j}$ for region $i$

$i=1, \ldots n=$ the number of regions

$j=1, \ldots, m=$ the number of pillars.

The penalizing feature reflects the belief that the entrepreneurial performance of each region is mainly determined by its weakest component(s), and all other pillars with higher values cannot exploit their full potential because of the existence of bottleneck in their system of entrepreneurship.

7. Sub-index calculation: The pillars are the basic building blocks of the subindex. There are three: entrepreneurial attitudes, entrepreneurial abilities, and entrepreneurial aspirations. The value of a sub-index for any region is the penalty weighted average of its average equalized pillars for that sub-index multiplied by 100. The maximum value of the sub-indices is 100 and the potential minimum is 0 , both of which reflect the relative position of a region in a particular sub-index.

$$
\begin{aligned}
\mathrm{ATT}_{i} & =100 \sum_{j=1}^{5} h_{i, j} \\
\mathrm{ABT}_{i} & =100 \sum_{j=6}^{9} h_{i, j} \\
\mathrm{ASP}_{i} & =100 \sum_{j=10}^{14} h_{i, j}
\end{aligned}
$$

where $h_{i, j}$ is the modified, post-penalty value of pillar $j$ in region $i$ $i=1, \ldots, n=$ the number of regions $j=1, \ldots, 14=$ the number of pillars.

8. REDI score calculation: The super-index, the REDI, is the simple average of the three sub-indices. Since 100 represents the theoretically available limit, the GEDI points can also be interpreted as a measure of the efficiency of the entrepreneurship inputs

$$
\mathrm{REDI}_{i}=\frac{1}{3}\left(\mathrm{ATT}_{i}+\mathrm{ABT}_{i}+\mathrm{ASP}_{i}\right)
$$

where $\mathrm{REDI}_{i}$ is the Regional Entrepreneurship and Development Index score of region $i$

$i=1,2, \ldots, n=$ the number of regions. 
From the policy perspective, REDI methodology has two key features. The first is the average equalization methodology (Point 5) that is designed to equalize the marginal effects of the additional inputs over the average of 14 pillars while keeping all the values in the $[0,1]$ range. This means that after transformation, below average (0.49) pillar values increased (Opportunity Perception, Networking, Technology Absorption, Human Capital and Finance) and all the other pillar values decreased. Consequently, improving the originally below average pillar value requires a smaller absolute increase of additional inputs as compared to the originally higher average pillar value where a larger increase is necessary for the same marginal improvement.

\section{References}

Acs ZJ, Audretsch DB, Braunerhjelm P, Carlsson B (2009) The knowledge spillover theory of entrepreneurship. Small Bus Econ 32:15-30

Acs ZJ, Autio E, Szerb L (2014) National systems of entrepreneurship: measurement issues and policy implications. Res Policy 43:476-494. https://doi.org/10.1016/j.respol.2013.08.016

Acs Z, Estrin S, Mickiewicz T, Szerb L (2017) Institutions, entrepreneurship and growth: the role of national entrepreneurial ecosystems. Small Bus Econ (Forthcoming)

Alvedalen J, Boschma R (2017) A critical review of entrepreneurial ecosystems research: towards a future research agenda. Eur Plan Stud 25:887-903. https://doi.org/10.1080/09654313.2017. 1299694

Anselin L, Varga A, Acs Z (1997) Local geographic spillovers between university research and high technology innovations. J Urban Econ. 42(3):422-448

Audretsch DB, Kuratko DF, Link AN (2015) Making sense of the elusive paradigm of entrepreneurship. Small Bus Econ 45(4):703-712

Autio E, Pathak S, Wennberg K (2013) Consequences of cultural practices for entrepreneurial behaviors. J Int Bus Stud 44(4):334-362

Baum JR, Frese M, Baron RA (2014) Born to be an entrepreneur? Revisiting the personality approach to entrepreneurship. In: The psychology of entrepreneurship. Psychology Press, pp 73-98

Baumol WJ (1996) Entrepreneurship: productive, unproductive, and destructive. J Bus Ventur 11(1):3-22

Bayar A (2007) Simulation of R\&D investment scenarios and calibration of the impact on a set of multi-country models. European Commission DG JRC Institute for Prospective Technological Studies (IPTS)

Bradley J (2006) Evaluating the impact of european union cohesion policy in less-developed countries and regions. Reg Stud 40:189-199

ESRI (2002) An examination of the ex-post macroeconomic impacts of CSF 1994-1999 on Objective 1 countries and regions

Fujita M, Krugman PR, Venables AJ (1999) The spatial economy: cities, regions and international trade. Wiley Online Library

Gartner WB (1985) A conceptual framework for describing the phenomenon of new venture creation. Acad Manag Rev 10(4):696-706

Joint Research Centre-European Commission (2008) Handbook on constructing composite indicators: methodology and user guide. OECD publishing

Krugman P (1991) Increasing returns and economic geography. J Polit Econ 99(3):483-499. https:// doi.org/10.2307/2937739 
Lafuente E, Szerb L, Acs ZJ (2016) Country level efficiency and national systems of entrepreneurship: a data envelopment analysis approach. J Technol Transfer 41(6):1260-1283

Lafuente E, Acs Z, Sanders M, Szerb L (2019) The global technology frontier: productivity growth and the relevance of Kirznerian and Schumpeterian entrepreneurship. Small Bus Econ 1-26. Online https://doi.org/10.1007/s11187-019-00140-1

Landström H, Harirchi G (2018) The social structure of entrepreneurship as a scientific field. Res Policy 47(3):650-662

Liñán F, Fernandez-Serrano J (2014) National culture, entrepreneurship and economic development: different patterns across the European Union. Small Bus Econ 42(4):685-701

Low MB, MacMillan IC (1988) Entrepreneurship: past research and future challenges. J Manag 14(2):139-161

Malecki EJ (2018) Entrepreneurship and entrepreneurial ecosystems. Geography Compass. Online access, pp 1-21. https://doi.org/10.1111/gec3.12359

Naudé W (2010) Entrepreneurship, developing countries, and development economics: new approaches and insights. Small Bus Econ 34(1):1

Nightingale P, Coad A (2014) Muppets and gazelles: political and methodological biases in entrepreneurship research. Ind Corp Change 23:113-143. https://doi.org/10.1093/icc/dtt057

Parker SC (2018) The economics of entrepreneurship. Cambridge University Press

Prieger JE, Bampoky C, Blanco LR, Liu A (2016) Economic growth and the optimal level of entrepreneurship. World Dev 82:95-109

Qian H, Acs ZJ, Stough RR (2013) Regional systems of entrepreneurship: the nexus of human capital, knowledge and new firm formation. J Econ Geogr 13:559-587. https://doi.org/10.1093/ jeg/lbs009

Rappai G, Szerb L (2011) Összetett indexek készítése új módon: a szúk keresztmetszetekért történő büntetés módszere. PTE KRTI Múhelytenulmányok 2011/1

Ratto M, Roeger W, in't Veld J (2009) QUEST III: an estimated open-economy DSGE model of the euro area with fiscal and monetary policy. Econ Model 26:222-233

Romer P (1990) Endogenous technological change. J Polit Econ 98:71-102

Sanders M, Stenkula M, Grilli L, Herrmann AM, Latifi G, Páger B, Szerb L, Terragno Bogliaccini E (2020a) A Reform Strategy for Italy. In: Sanders M, Marx A, Stenkula M(eds) The entrepreneurial society. Springer, Berlin Heidelberg

Sanders M, Stenkula M, Fritsch M, Herrmann AM, Latifi G, Páger B, Szerb L, Terragno Bogliaccini E, Wyrwich M (2020b) A Reform Strategy for Germany. In: Sanders M, Marx A, Stenkula M (eds) The entrepreneurial society. Springer, Berlin Heidelberg

Sanders M, Stenkula M, Dunstan J, Estrin S, Herrmann AM, Páger B, Szerb L, Terragno Bogliaccini E (2020c) A Reform Strategy for the UK. In: Sanders M, Marx A, Stenkula M (eds) The entrepreneurial society. Springer, Berlin Heidelberg

Schalk H, Varga A (2004) The economic effects of EU community support framework interventions. An Ex-ante Impact Analysis with EcoRET, A Macroeconomic Model For Hungary. Center of Applied Economic Research Münster (CAWM), University of Münster

Sebestyén T, Varga A (2013) Research productivity and the quality of interregional knowledge networks. Ann Reg Sci 51:155-189

Shane S, Venkataraman S (2000) The promise of entrepreneurship as a field of research. Acad Manag Rev 25(1):217-226

Spigel B (2017) The relational organization of entrepreneurial ecosystems. Entrepreneurship Theory Pract 41(1):49-72

Stam E (2015) Entrepreneurial ecosystems and regional policy: a sympathetic critique. Eur Plan Stud 23:1759-1769. https://doi.org/10.1080/09654313.2015.1061484

Szerb L, Vörös Zs, Komlósi É, Acs ZJ, Páger B, Ortega-Argilés R, Abaligeti G (2017) The new regional entrepreneurship and development index: structure, data and description of methodology. Unpublished manuscript 
Szerb LE, Lafuente K Horváth, Páger B (2018) The relevance of quantity and quality entrepreneurship for regional performance: the moderating role of the entrepreneurial ecosystem. Reg Stud . https://doi.org/10.1080/00343404.2018.1510481

Treyz G, Rickman D, Shao G (1992) The REMI economic-demographic forecasting and simulation model. Int Reg Sci Rev 14:221-253

Varga A (2000) Local academic knowledge transfers and the concentration of economic activity. J Reg Sci 40(2):289-309

Varga A (2006) The spatial dimension of innovation and growth: empirical research methodology and policy analysis. Eur Plan Stud 14(9):1171-1186. https://doi.org/10.1080/ 09654310600933298

Varga A (2007) GMR-Hungary: a complex macro-regional model for the analysis of development policy impacts on the Hungarian economy. PTE KTK KRTI Working Papers (2007/4)

Varga A (2017a) Geographical macro and regional impact modeling. In: Jackson R, Schaeffer P (eds) Regional research frontiers, advances in spatial science, vol 2, pp 49-58. https://doi.org/10. 1007/978-3-319-50590-9_3

Varga A (2017b) Place-based, spatially blind, or both? Challenges in estimating the impacts of modern development policies: the case of the GMR policy impact modeling approach. Int Reg Sci Rev 40:12-37. https://doi.org/10.1177/0160017615571587

Varga A, Baypinar M (2016) Economic impact assessment of alternative European neighborhood policy (ENP) options with the application of the GMR-Turkey model. Ann Reg Sci 56:153-176

Varga A, Sebestyén T, Szabó N, Szerb L (2018) Economic Impact assessment of Entrepreneurship policies with the GMR-Europe Model. FIRES Project Report D4.6, 2018.04.06

Varga A, Sebestyén T, Szabó N, Szerb L (2019) Estimating the economic impacts of knowledge network and entrepreneurship development in smart specialization policy. Reg Stud. https://doi. org/10.1080/00343404.2018.1527026

Vivarelli M (2013) Is entrepreneurship necessarily good? Microeconomic evidence from developed and developing countries. Ind Corp Change 22:1453-1495. https://doi.org/10.1093/icc/dtt005

Wennekers S, Thurik R (1999) Linking entrepreneurship and economic growth. Small Bus Econ 13(1):27-56

Open Access This chapter is licensed under the terms of the Creative Commons Attribution 4.0 International License (http://creativecommons.org/licenses/by/4.0/), which permits use, sharing, adaptation, distribution and reproduction in any medium or format, as long as you give appropriate credit to the original author(s) and the source, provide a link to the Creative Commons license and indicate if changes were made.

The images or other third party material in this chapter are included in the chapter's Creative Commons license, unless indicated otherwise in a credit line to the material. If material is not included in the chapter's Creative Commons license and your intended use is not permitted by statutory regulation or exceeds the permitted use, you will need to obtain permission directly from the copyright holder.

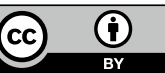

